\title{
Pivotal Role of Nitric Oxide in the Control of Blood Pressure After Leptin Administration
}

\author{
Gema F rühbeck
}

\begin{abstract}
Leptin administration has been shown to increase renal, adrenal, and lumbar sympathetic nerve activity. However, this generalized sympathoexcitatory activity is not always followed by an increase in arterial pressure. The present study tested the hypothesis that leptin induces a release of nitric oxide ( $\mathrm{NO}$ ) that opposes the pressor effect of sympathoex citation. The effect of intravenous administration of leptin $(10,100$, and $1,000 \mu \mathrm{g} / \mathrm{kg}$ body wt) or vehicle on blood pressure (BP), heart rate (HR), and serum nitrite/nitrate concentrations of anesthetized Wistar rats was examined. At 90 min after injection, the three leptin doses tested increased serum NO concentrations 20.5,33.1, and $89.5 \%$, respectively ( $P<0.001$ vs. baseline). The effect of leptin on NO concentrations was significantly dosedependent on linear trend testing $(P=0.0001)$. In contrast, leptin did not change serum nitrite/nitrate concentrations of $\mathrm{fa} / \mathrm{fa}$ rats. Leptin administration to Wistar rats under $\mathbf{N O}$ synthesis inhibition ( $\mathbf{N}^{\omega}$-nitro-Larginine methyl ester [L-NAME]) produced a statistically significant increase $(P<0.05)$ in both systolic B P and mean arterial pressure as well as in $H R$ $(P<0.01)$. Injection of leptin into rats with pharmacologically induced ganglionic blockade (chlorisondamine) was followed by a decrease in BP and HR to values significantly lower $(P<0.01)$ than those observed with chlorisondamine treatment alone. The leptininduced hypotension observed in the setting of ganglionic blockade was blocked by L-NAME. These findings raise the possibility that the leptin-induced release of NO may contribute to the homeostasis of BP. Diabetes 48:903-908, 1999
\end{abstract}

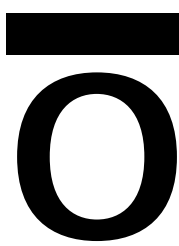

besity is associated with an increased incidence of hypertension and cardiovascular mortality (1-3). However, the mechanisms that link obesity with altered renal function and high blood pressure (BP) have not been fully elucidated. The adipocytederived hormone leptin has been suggested to be implicated in obesity-related hypertension (4). Intracerebroventricular as well as chronic intravenous administration of leptin have

From the Department of Endocrinology, Clínica Universitaria de Navarra, University of Navarra, Pamplona, Spain

Address correspondence and reprint requests to Dr. Gema Frühbeck, Department of Endocrinology, Clínica Universitaria de Navarra, 31008 Pamplona, Spain. E-mail: gfruhbeck@unav.es.

Received for publication 26 October 1998 and accepted in revised form 23 December 1998.

ANOVA, analysis of variance; BAT, brown adipose tissue; BP, blood pressure; $C N S$, central nervous system; $d B P$, diastolic blood pressure; $H R$, heart rate; L-NAME, $\mathrm{N}^{\omega}$-nitro-L-arginine methyl ester; MAP, mean arterial pressure; NOS, nitric oxide synthase; NPY, neuropeptide Y; SBP, systolic blood pressure. been shown to increase both mean arterial pressure (MAP) and heart rate (HR) (5-7). However, some studies have reported that MAP and HR were not changed by acute leptin infusion (7-9).

Because leptin binding sites have been found in brain regions that are also important in cardiovascular control (10), there is reason to suspect that leptin may affect cardiovascular function through its effects on the central nervous system (CNS). This possibility is supported by the observation that leptin administration increases sympathetic nerve activity to kidneys, adrenals, and brown adipose tissue (BAT) $(5,8)$. However, leptin has also been shown to cause natriuresis and diuresis after bolus intravenous infusion (9). Thus, leptin may be influencing different regulatory pathways that have opposite effects on BP control.

Recently, it has been reported that the functional leptin receptor OB-R $\mathrm{b}$ is expressed in endothelial cells and that it is functionally competent (11). This provides evidence that the endothelium is a target for leptin action. The vascular endothelium is known to play a critical role in BP homeostasis, in part by its ability to produce potent vasoactive factors, principal among these being the vasodilator nitric oxide (NO) (12). The aim of this study, therefore, was to assess the possible role of NO in the leptin-induced effects on BP regulation in Wistar normotensive rats. Several doses of leptin were used, and serum nitrite/nitrate concentrations were measured to delineate a concentration-response relationship. Pretreatment with $\mathrm{N}^{\omega}$-nitro-L-arginine methyl ester (L-NAME) and chlorisondamine was also performed to study the effects of leptin on BP under NO synthesis inhibition and acute ganglionic blockade, respectively. In addition, the effects of leptin on BP, HR, and serum nitrite/nitrate concentrations were examined in obese Zucker rats, which have a mutation in the leptin receptor gene.

\section{RESEARCH DESIGN AND METHODS}

Animals and surgical instrumentation. The animals used in this study were 3-month-old male Wistar and obese Zucker (fa/fa) rats (Harlan, Bicester, Oxon, U.K.). All experimental procedures conformed to the $\mathrm{N}$ ational Institutes of Health Gui defor the Careand Use of Laboratory Ani mals.

Animals were anesthetized with an intraperitoneal injection of sodium pentobarbital ( $50 \mathrm{mg} / \mathrm{kg}$ body wt) and received an intramuscular prophylactic dose of penicillin $\mathrm{G}(20,000 \mathrm{U})$ before surgery. The trachea was cannulated to minimize respiratory difficulties. A small incision was made in the groin for placing a cannula in the femoral vein for drug infusion and blood sampling. A catheter was inserted in the femoral artery for measurement of arterial pressure. The catheter was filled with heparinized saline $(1,000 \mathrm{U} / \mathrm{ml})$. Maintenance of anesthesia was achieved with intravenous chloralose $\left(25 \mathrm{mg} \cdot \mathrm{kg}^{-1} \cdot \mathrm{h}^{-1}\right)$. Rats were prepared for cardiovascular recording and were allowed to stabilize on a pad heated to maintain the body temperature at $37.5 \pm 0.5^{\circ} \mathrm{C}$.

Study design. Four separate groups of Wistar rats ( $n=8$ per group) received intravenously one of three doses of leptin or vehicle in a bolus injection. The leptin doses tested were 10,100, and 1,000 $\mu \mathrm{g} / \mathrm{kg}$ body wt. Leptin was dissolved in phosphate-buffered $0.9 \%$ saline, which was used as the control infusion. The 
TABLE 1

Hemodynamic data obtained from Wistar rats at baseline and 90 min after intravenous administration of saline or leptin

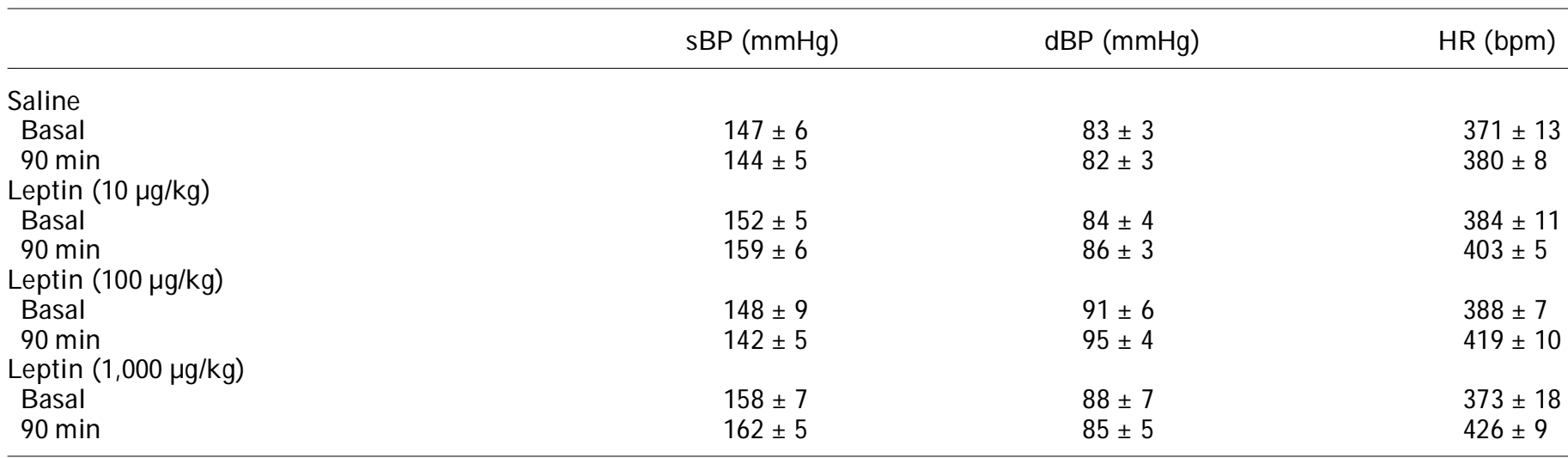

Data are means \pm SE ( $n=8$ per group). No statistically significant differences from baseline were found (Student's $t$ test).

possible effect of the bacterial lipopolysaccharide present in the recombinant mouse leptin on hemodynamic and sympathetic parameters has already been tested and excluded by Haynes et al. (8).

The effects of administration of a physiological dose of leptin $(100 \mu \mathrm{g} / \mathrm{kg})$ were examined in four additional experimental groups of Wistar rats with NO synthase (NOS) inhibition or ganglionic blockade. NOS was blocked with a single intravenous bolus injection ( $30 \mathrm{mg} / \mathrm{kg}, \mathrm{n}=16$ ) of L-NAME, since it has been reported to evoke in rats a maximal increase of $B P$, which reaches a plateau in 6 min (13). At $10 \mathrm{~min}$ after L-NAME administration, when steady pressure values had been reached, animals received either saline $(0.9 \%, \mathrm{n}=8)$ or leptin $(100 \mu \mathrm{g} / \mathrm{kg}, \mathrm{n}=8)$. Pretreatment with the ganglion-blocking agent chlorisondamine $(30 \mathrm{mg} / \mathrm{kg}$ i.v., $\mathrm{n}=16)$ was followed by a bolus intravenous injection of either saline $(0.9 \%$ $\mathrm{n}=8)$ or leptin $(100 \mu \mathrm{g} / \mathrm{kg}, \mathrm{n}=8)$. Chlorisondamine was chosen because it is known to produce a complete and irreversible ganglionic blockade (14). Vehicle and leptin were injected $10 \mathrm{~min}$ after the administration of chlorisondamine, at which time steady levels of BP had been achieved. In a subset of rats, the effect of L-NAME administration ( $30 \mathrm{mg} / \mathrm{kg}$ i.v., $\mathrm{n}=5$ ) on the leptin-induced changes in $\mathrm{BP}$ was studied in the setting of acute ganglionic blockade.

To establish that the effects of leptin on NO release are mediated through leptin receptors, obese fa/fa rats, which lack functional leptin receptors, were injected with the highest leptin dose previously used $(1,000 \mu \mathrm{g} / \mathrm{kg}$ i.v., $\mathrm{n}=5)$. To ensure that the fa/fa rat is able to release $\mathrm{NO}$ in response to other agents, sodium nitroprusside $(4 \mu \mathrm{g} / \mathrm{kg}$ i.v., $\mathrm{n}=5)$, a known NO donor, was tested as a positive control.

Hemodynamic recording, blood sampling, and NO determination. Arterial pressure was measured in anesthetized rats via a pressure transducer (Statham P23AA; Oxnard, CA) connected to a polygraph (Beckman R511A; Fullerton, CA) Baseline measurements of arterial BP and HR were made for 5 min on three occasions. A blood sample was obtained for analysis of basal serum NO concentration. At 90 min after administration of leptin or vehicle, BP and $H R$ were recorded and another venous blood sample was collected. The withdraw $n$ blood was transferred to glass serum separation tubes, allowed to clot at room temperature $\left(22^{\circ} \mathrm{C}\right)$, and centrifuged $(1,200 \mathrm{~g})$ for $10 \mathrm{~min}$

NO was determined photometrically in serum by its oxidation products nitrite and nitrate using a colorimetric assay (Boehringer Mannheim Mannheim, Germany). As described by the manufacturer, NO is detected in biological fluids via nitrite. The nitrate present in samples is reduced to nitrite by reduced nicotinamide adenine dinucleotide phosphate in the presence of the enzyme nitrate reductase (15). The nitrite formed reacts with sulfanilamide and $\mathrm{N}$-(1-naphtyl)-ethyl-enediamine dihydrochloride to give a red-violet diazo dye. Finally, the diazo dye is measured based on its absorbance at $550 \mathrm{~nm}$ using a microtiter plate reader.

Drugs. Recombinant murine leptin was purchased from PeproTech (London, U.K.). The OB protein showed more than $95 \%$ purity, as evidenced by SDS-PAGE and high-performance liquid chromatography analyses. L-NAME and sodium nitroprusside were obtained from Sigma (St. Louis, MO). Chlorisondamine was acquired from Ciba-Geigy (Basel, Switzerland). All drugs were made fresh on the day of the experiment, and all solutions were infused through a Millipore filter ( $22 \mu \mathrm{m}$, Cathivex; Bedford, MA).

Data analysis. Results are expressed as means \pm SE. BP and HR values from the three separate baseline measurements did not differ significantly for any parameter and were therefore averaged for each animal. Basal values in the control and leptin-treated rats were compared by two-tailed unpaired Student's t test, and changes from baseline were analyzed by two-tailed paired Student's t test. Dif- ferences between leptin-treated and control animals were assessed using a repeated measures analysis of variance (ANOVA), with statistical testing by Scheffe's $F$ test. Dose-dependency was tested by a factorial ANOVA using linear trend testing. Analyses were performed using the StatView 4.01 Non-FPU (Abacus Concepts, 1992-1993) statistical package for Apple Macintosh computers. A value of $\mathrm{P}<0.05$ was considered statistically significant.

\section{RESULTS}

E ffects of leptin doses on hemodynamics and serum nitrite/nitrate. No differences in baseline systolic or diastolic arterial pressure or HR were observed between rats treated with saline and those treated with leptin (Table 1). Arterial pressure did not change significantly in any group after leptin or saline administration. In the three leptintreated groups (10,100, and $1,000 \mu \mathrm{g} / \mathrm{kg}$ body wt), there was



FIG. 1. Dose-response curve showing percentage increase from baseline in serum nitrite/nitrate concentrations of Wistar rats $90 \mathrm{~min}$ after intravenous injection of $0.9 \%$ saline and three doses of leptin. $* * * P<0.001$ vs. baseline by Student's t test; $\S \mathrm{P}<0.05$, $\S \S \S \mathrm{P}<0.001$ vs. saline by ANOVA. Values are means \pm SE ( $n=8$ per group). 
a tendency for HR to increase 90 min after drug injection, but the magnitude of the increase did not reach statistical significance $(P=0.066, P=0.078, P=0.093$, respectively).

It is noteworthy to point out that intravenous administration of leptin increased serum nitrite/nitrate concentrations, with an $89.5 \pm 12.5 \%$ increase in the first $90 \mathrm{~min}$ after the $1,000 \mu \mathrm{g} / \mathrm{kg}$ dose ( $P<0.001$ vs. saline) (Fig. 1). Lower doses of leptin produced more modest increases in serum nitrite/nitrate levels, which were significantly different from baseline $(P$ $<0.001)$ and from the saline control $(P<0.05)$. The effect of leptin on nitrite/nitrate concentrations was significantly dosedependent on linear trend testing $(P=0.0001)$ (Fig. 1).

No statistically significant changes were observed in MAP and HR between saline- or leptin-treated fa/fa rats (MAP: $118 \pm 5$ vs. $122 \pm 6$ mmHg; HR: $372 \pm 14$ vs. $383 \pm 16$ bpm, respectively). Administration of leptin did not alter nitrite/nitrate concentrations relative to basal values in Zucker rats ( $13.8 \pm 0.9$ vs. $15.3 \pm 1.0 \mu \mathrm{mol} / \mathrm{l}$, respectively). However, injection of sodium nitroprusside into fa/fa rats produced a statistically significant increase $(P<0.01)$ in serum nitrite/nitrate concentrations $(21.8 \pm 1.1 \mu \mathrm{mol} / \mathrm{l})$.

E ffects of leptin under NOS inhibition and acute ganglionic blockade. As expected, inhibition of NO synthesis produced an increase in both systolic BP (SBP) and diastolic $B P(\mathrm{dBP})$ in all rats receiving the $L-N A M E$ pretreatment (Table 2). At 10 min after L-NAME administration, MAP was increased and HR was reduced from control levels before drug injection. In the animals injected with the NOS inhibitor, MAP changed from $108 \pm 4$ to $149 \pm 5 \mathrm{mmHg}$, whereas HR decreased from $379 \pm 12$ to $341 \pm 10 \mathrm{bpm}$. Leptin administration to rats pretreated with L-NAME increased even more the already high $\mathrm{HR}$ and $\mathrm{BP}$ values (Table 2, Fig. $2)$. The statistically significant increase $(P<0.05)$ in SBP was accompanied by a clear tendency for an increase in $\mathrm{dBP}(\mathrm{P}$ $=0.0841$ ). This resulted in a statistically significant increase $(P<0.05)$ in MAP, which changed from $147 \pm 7$ to 170 $\pm 7 \mathrm{mmHg}$.

To observe the hemodynamic effects of leptin in the absence of simultaneous sympathoactivation, an acute ganglionic blockade was pharmacologically induced. Pretreat- ment with the ganglion-blocking agent chlorisondamine lowered both BP and HR in all rats (Table 2, Fig. 2). The initial hemodynamic parameters for the experimental group receiving saline were similar to those of animals injected with leptin. Administration of leptin decreased $B P$ and $H R$ to values significantly lower $(P<0.01)$ than those observed after ganglionic blockade alone. Vehicle injection produced no changes in arterial pressure and HR over time.

The effect of L-NAME injection in the setting of acute ganglionic blockade and leptin treatment was also studied to validate the underlying assumption that the hypotensive effect of leptin administration observed during ganglionic blockade is due to $\mathrm{NO}$ release. Figure 2 shows that the inhibitor of NOS blocked the leptin-mediated decrease in BP $(P<0.01)$ during pharmacologically induced acute ganglionic blockade.

\section{DISCUSSION}

The present study shows that leptin increases NO synthesis in a dose-dependent manner in male normotensive Wistar rats. Control of BP is achieved, at least in part, by a balance in factors affecting vasoconstriction and vasodilation. One of the most important factors controlling ongoing vasoconstriction is the sympathetic nervous system. It has been clearly shown that leptin infusion increases sympathetic nerve activity to BAT, kidney, hindlimb, and adrenal gland $(5,8)$. However, in some studies as well as in the present study, leptin did not increase arterial pressure, despite the increase in overall sympathetic nerve activity (7-9). In this context, Haynes et al. (8) suggested that leptin may have other effects that offset the expected vasoconstrictor effects of increased sympathetic outflow. The increase in serum NO concentrations observed in the present study after leptin administration could oppose the pressor effects of sympathoactivation. Thus, leptin may influence the balance between hypertensive and hypotensive mechanisms exerting a homeostatic control on BP by finely tuning the vascular tone in favor of vasoconstriction or vasodilation.

This is not the first study to report that leptin acts, at least in part, via NO. Yu et al. (16) showed that NO mediates lep-

TABLE 2

Hemodynamic data obtained from Wistar rats under NOS inhibition (L-NAME) or ganglionic blockade (chlorisondamine) at baseline and 90 min after intravenous administration of saline or leptin

\begin{tabular}{|c|c|c|c|}
\hline & $\mathrm{sBP}(\mathrm{mmHg})$ & $\mathrm{dBP}(\mathrm{mmHg})$ & $\mathrm{HR}(\mathrm{bpm})$ \\
\hline \multicolumn{4}{|c|}{ L-NAME (30 mg/kg) } \\
\hline \multicolumn{4}{|c|}{ +Saline } \\
\hline Basal & $196 \pm 8$ & $127 \pm 4$ & $345 \pm 9$ \\
\hline $90 \mathrm{~min}$ & $192 \pm 10$ & $121 \pm 9$ & $355 \pm 11$ \\
\hline \multicolumn{4}{|c|}{ +Leptin $(100 \mu \mathrm{g} / \mathrm{kg})$} \\
\hline Basal & $190 \pm 8$ & $125 \pm 9$ & $337 \pm 11$ \\
\hline $90 \min$ & $222 \pm 9 *$ & $145 \pm 10$ & $398 \pm 13 \dagger$ \\
\hline \multicolumn{4}{|c|}{ Chlorisondamine (30 mg/kg) } \\
\hline \multicolumn{4}{|c|}{ +Saline } \\
\hline Basal & $113 \pm 9$ & $52 \pm 4$ & $295 \pm 14$ \\
\hline $90 \min$ & $117 \pm 5$ & $55 \pm 3$ & $291 \pm 12$ \\
\hline \multicolumn{4}{|c|}{ +Leptin $(100 \mu \mathrm{g} / \mathrm{kg})$} \\
\hline Basal & $119 \pm 11$ & $58 \pm 2$ & $294 \pm 10$ \\
\hline $90 \mathrm{~min}$ & $95 \pm 8 \dagger$ & $44 \pm 4 \dagger$ & $248 \pm 6 \dagger$ \\
\hline
\end{tabular}

Data are means $\pm S E$ ( $n=8$ per group). $* P<0.05, \uparrow P<0.01$ statistically significant differences from baseline (Student's $t$ test). 


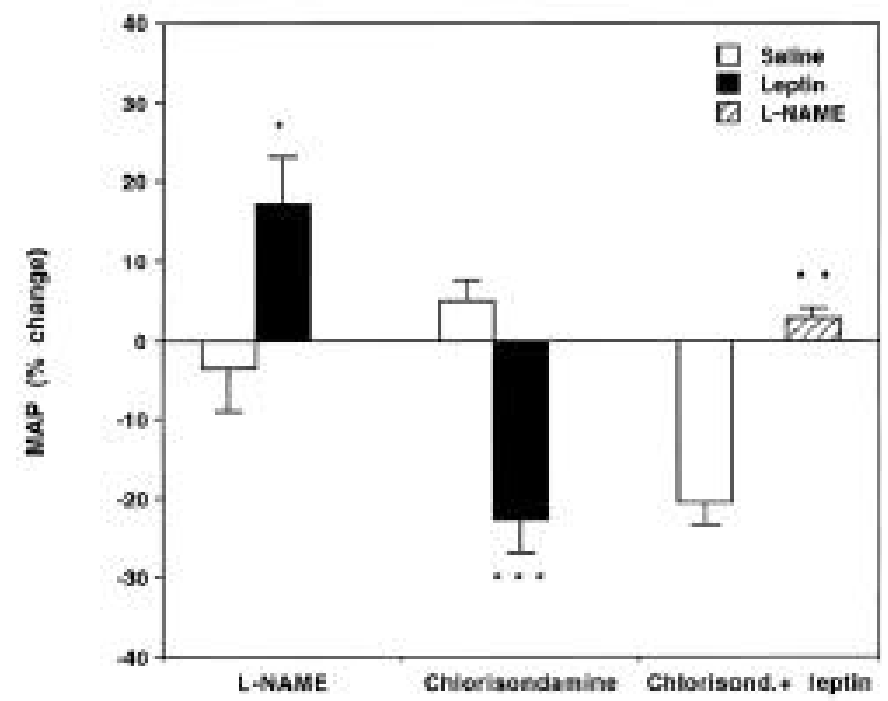

FIG . 2. Percent change from baseline in MAP of Wistar rats under NOS inhibition ( $\mathrm{L}-\mathrm{NAME}$; $30 \mathrm{mg} / \mathrm{kg}$ ) or acute ganglionic blockade (chlorisondamine; $30 \mathrm{mg} / \mathrm{kg}$ ). Results represent mean change $\mathbf{9 0}$ min after intravenous injection of vehicle $(0.9 \%$ saline $)$ or leptin $(100 \mu \mathrm{g} / \mathrm{kg})$. Values are means \pm SE ( $n=8$ per group). In a subset of rats $(n=5)$, the effect of an inhibitor of NOS ( L-NAME; $30 \mathrm{mg} / \mathrm{kg}$ ) was tested in the setting of ganglionic blockade and leptin pretreatment (chlorisondamine $[30 \mathrm{mg} / \mathrm{kg}]+$ leptin $[100 \mu \mathrm{g} / \mathrm{kg}])$. $* \mathbf{P}<0.02, * * \mathbf{P}<0.01, * * * \mathbf{P}<$ 0.001 vs. saline by Student's t test.

tin-induced luteinizing hormone-releasing hormone and luteinizing hormone release at the hypothalamic and pituitary level. The interpretation that leptin-induced NO release is involved in modulating $B P$ is further strengthened by the observations made after L-NAME pretreatment as well as pharmacologically induced ganglionic blockade. When the influence of leptin on NO release is blocked by NOS inhibition, the stimulatory effect of leptin on overall sympathetic nerve traffic clearly overweighs the vasodilatory influences, leading to even higher BP values than those observed with NOS blockade only. On the contrary, a marked hypotension is observed as a result of the effect of leptin on NO synthesis predominating over the lacking adrenergic-mediated vasoconstriction during acute ganglionic blockade. Moreover, the present study also shows that an inhibitor of NOS reverses the hypotension after leptin administration in the setting of ganglionic blockade. Thus, the leptin-induced NO increase may play a critical role in regulating the hemodynamic adjustments in response to the leptin-mediated sympathoactivation. Recently, it has been shown that leptin increases endothelial production of NO in isolated aortic rings (17). This effect was not observed in rings denuded of endothelium or treated with L-NAME (17).

In Zucker rats-the mutant rats that lack functional leptin receptors- administration of leptin did not alter SBP or dBP. This observation is in agreement with the study of Haynes et al. (8) showing that obese Zucker rats treated with leptin did not experience changes in BP. These researchers further showed that, in contrast to their lean littermates, obese Zucker rats exhibited markedly blunted renal and BAT sympathetic nerve activity responses to leptin. While injection of leptin into obese Zucker rats was not followed by changes in nitrite/nitrate concentrations, administration of sodium nitro- prusside produced an increase in serum nitrite/nitrate levels relative to basal values in the present study. Thus, the fa/fa rat is able to release NO in response to sodium nitroprusside, a known NO donor, but not in response to leptin. Taken together, all these facts show that the effects of leptin on BP, NO release, and sympathetic nerve activation seem to require functional leptin receptors.

The finding of an increase in serum NO concentrations at 90 min after a single intravenous injection of leptin indicates that leptin exerts a role of physiological relevance in shortterm cardiovascular regulation. This observation complements the study of Shek et al. (6) reporting the CNS and peripheral effects of leptin in long-term BP control. Leptin is a good example of extreme functional pleiotropy. Originally identified by its effects on food intake and body weight regulation, leptin has subsequently been shown to be capable of stimulating a variety of biological responses in a wide spectrum of cell types. As far as BP control is concerned, leptin increases sympathetic nerve activation $(5,8)$, causes natriuresis and diuresis (9), and seems to be involved in endothelial NO release.

There are several potential limitations of this study that need to be addressed. First, the experiments were performed by using recombinant mouse leptin in Wistar rats, and the effects of rat leptin may be different. However, it has been shown that the nucleotide sequence of the coding region of rat ob gene is highly homologous to the mouse gene $(95 \%$ at the nucleotide level and $96 \%$ at the protein level) (18). Also, murine leptin has been shown to be biologically active in rats in an experiment (8) similar to this one as well as in other studies (e.g., 19). Second, because the animals were anesthetized, it could be argued that different results would be obtained under more physiological circumstances. To address this concern requires performing the same study in conscious unrestrained rats. Third, the effect on NO was determined by measuring serum nitrite/nitrate concentrations, which is not a sensitive method for detecting low doses of NO produced by an activation of endothelial NOS. However, since changes were clearly observed with this method, it may mean that even more marked differences might have been obtained with a more sensitive technique.

The present study does not indicate whether the leptininduced NO increase observed is due to a direct effect of leptin or secondary to an interaction with other physiological factors. Interestingly, leptin has been shown to present striking structural similarities to members of the long-chain helical cytokine family $(20,21)$, and several investigators have demonstrated the existence of a cytokine-inducible Larginine/NO pathway $(22,23)$. A part from the direct actions of NO on vascular smooth muscle, additional roles for NO in the regulation of cardiovascular functions have been proposed. Several groups have reported an inhibitory effect of NO on sympathetic outflow in vivo, suggesting a peripheral modulation of the sympathetic vasoconstriction by NO that is independent of the degree of central sympathetic nerve activity (24-26). Direct evidence for the role of neuropeptideY (NPY) in sympathetic nerve stimulation-induced vasoconstriction has also been provided (27). NPY is known to produce contraction of vascular smooth muscle cells, both directly and by potentiating the effects of other vasoconstrictors. Recently, NPY Y 1 receptors have been shown to mediate this response (28). Leptin has been shown to inhibit 
the synthesis and release of NPY (29). Thus, leptin may, in addition to increasing the concentration of $\mathrm{NO}$, attenuate the vasoconstrictor effect of NPY. Conversely, the effects of leptin observed in the present study could be explained as the effects of an NPY decrease.

Because leptin's effects on NO synthesis appear to be protective against the development of high $\mathrm{BP}$, it may be argued that if the vasculature is resistant to leptin's actions, it may be involved in the development and/or maintenance of arterial hypertension. Therefore, a defect in the leptin system may contribute to hypertension as well as obesity. The increased incidence of hypertension observed in obesity may be explained by a hampered NO-modulation of a compensatory hypertensive response. This possibility is supported by findings made in both animal models and humans. It has been reported that obesity-related hypertension is associated with attenuated arterial dilation (30). Furthermore, NOS activity has been shown to be decreased in obese Zucker rats compared with littermate control rats (31), and the J CR:LA corpulent rat shows a defective NO-mediated vascular relaxation (32). In humans, an impaired endothelium-derived NO synthesis in obesity has been shown (33). In addition, an impaired NO-mediated vasodilation has been reported in elderly subjects, being that high BP is more commonly associated with old age (34). How ever, it remains unclear to what extent sympathetic vasoconstriction is actually curtailed by NO under pathophysiological circumstances and whether this effect differs among vascular beds.

In summary, this study provides evidence that an intravenous bolus injection of leptin increased nitrite/nitrate concentrations in a dose-dependent manner in normotensive Wistar rats. This effect needed functionally competent leptin receptors, since the leptin-induced increase in nitrite/nitrate levels could not be replicated in obese Zucker rats, which have a mutation in the leptin receptor gene. Leptin administration also increased MAP in L-NAME-treated Wistar rats and decreased MAP in rats with pharmacologically induced ganglionic blockade. Thus, leptin appears to have a balanced effect on BP with a pressor response attributable to sympathetic activation and a depressor response attributable to NO release. The present study envisages, for the first time, the possibility that leptin is involved in the control of vascular tone by simultaneously producing a neurogenic pressor action and an opposing NO-mediated depressor effect.

\section{ACKNOWLE DGMENTS}

The author gratefully acknowledges The Royal Society of London and the Spanish Ministry of Education and Culture for financial support.

\section{RE FERE NCES}

1. Ascherio A, Rimm EB, Giovannucci EL, Colditz GA, Rosner B, Willett WC, Sacks F, Stampfer MJ : A prospective study of nutritional factors and hypertension among U.S. men. Circulation 86:1475-1484, 1992

2. Hall J E: Renal and cardiovascular mechanisms of hypertension in obesity. Hypertensi on 23:381-394, 1994

3. Hsueh WA, Buchanan TA: Obesity and hypertension. Endocr Hypertens 23:405-427, 1994

4. Haynes WG, Sivitz WI, Morgan DA, Walsh SA, Mark AL: Sympathetic and cardiorenal actions of leptin. Hypertensi on 30:619-623, 1997

5. Dunbar J C, Hu Y, Lu H: Intracerebroventricular leptin increases lumbar and renal sympathetic nerve activity and blood pressure in normal rats. Diabetes 46:2040-2043, 1997

6. Shek EW, Brands MW, Hall J E: Chronic leptin infusion increases arterial pres- sure. Hypertensi on 31:409-414, 1998

7. Casto RM, Van Ness J M, Overton J M: Effects of central leptin administration on blood pressure in normotensive rats. Neurosci Lett 246:29-32, 1998

8. Haynes WG, Morgan DA, Walsh SA, Mark AL, Sivitz WI: Receptor-mediated regional sympathetic nerve activation by leptin.J Clin Invest 100:270-278, 1997

9. J ackson EK, Li P: Human leptin has natriuretic activity in the rat. AmJ Phys iol 272:F333-F 338, 1997

10. Tartaglia LA, Dembski M, Weng X, Deng N, Culpepper J , Devos R, Richards GJ , Campfield LA, Clark FT, Deeds ] , Muir C, Sanker S, Moriarty A, MooreKJ , Smutko J S, Mays GG, Woolf EA, Monroe CA, Tepper RI: Identification and expression cloning of a leptin receptor, OB-R. Cell 83:1263-1271, 1995

11. Sierra-Honigmann MR, Nath AK, Murakami C, García-Cardeña G, Papapetropoulos A, Sessa WC, Madge LA, Schechner J S, Schwabb MB, Polverini PJ , Flores-Riveros J R: Biological action of leptin as an angiogenic factor. Sci ence281:1683-1686, 1998

12. Moncada S, Palmer RMJ, Higgs EA: The discovery of nitric oxide as the endogenous nitrovasodilator. Hypertensi on 12:365-372, 1988

13. Rees DD, Palmer RMJ , Schulz R, Hodson HF, Moncada S: Characterization of three inhibitors of endothelial nitric oxide synthase in vitro and in vivo. $\mathrm{Br} J$ Pharmacol 101:746-752, 1990

14. Sander M, Hansen PG, Victor RG: Sympathetically mediated hypertension caused by chronic inhibition of nitric oxide. Hypertensi on 26:691-695, 1995

15. Stamler J S, Singel DJ , Loscalzo J : Biochemistry of nitric oxide and its redoxactivated forms. Sci ence 258:1898-1902, 1992

16. Yu WH, Walczewska A, Karanth S, McCann SM: Nitric oxide mediates leptininduced luteinizing hormone-releasing hormone (LHRH) and LHRH and leptin-induced $\mathrm{LH}$ release from the pituitary gland. Endocrinology 138:5055-5058, 1997

17. Lembo G, Vecchione C, Fratta L, Marino G, De Santis D, Trimarco B: Leptin induces nitric oxide-mediated vasorelaxation in aortic rings of WKY rats (Abstract). Hypertensi on 32:599, 1998

18. Funahashi T, Shimomura I, Hiraoka H, Arai T, Takahashi M, Nakamura T, Nozaki S, Yamashita S, Takemura K, Tokunaga K, Matsuzawa Y: Enhanced expression of rat obese (ob) gene in adipose tissues of ventromedial hypothalamus (VMH)-lesioned rats. Bi ochem Bi ophys Res Commun 211:469-475, 1995

19. Frühbeck G, Aguado M, Martínez JA: In vitro lipolytic effect of leptin on mouse adipocytes: evidence for a possible autocrine-paracrine role of leptin. Biochem Bi ophys Res Commun 240:590-594, 1997

20. Madej T, Boguski MS, Bryant SH:Threading analysis suggests that the obese gene product may be a helical cytokine. FEBS Lett 373:13-18, 1995

21. Zhang F, Basinski MB, Beals J M, Briggs SL, Churgay LM, Clawson DK, DiMarchi RD, F urman TC, Hale JE, Hsiung HM, Schoner BE, Smith DP, Zhang $X Y$, Wery J -P, Schevitz RW: Crystal structure of the obese protein leptin-E 100. Nature 387:206-209, 1997

22. Hibbs J B J r, Westenfelder C, Taintor R, Vavrin Z, Kablitz C, Baranowski RL, Ward J H, Menlove RL, MCMurry MP, Kushner JP, Samlowski WE : Evidence for cytokine-inducible nitric oxide synthesis from L-arginine in patients receiving interleukin-2 therapy. J Clin Invest 89:867-877, 1992

23. López-Talavera J C, Levitzki A, Martínez M, Gazit A, E steban R, Guardia J : Tyrosine kinase inhibition ameliorates the hyperdynamic state and decreases nitric oxide production in cirrhotic rats with portal hypertension and ascites. J Clin Invest 100:664-670, 1997

24. Sakuma I, Togashi H, Yoshioka M, Saito H, Yanagida M, Tamura M, Kobayashi $T$, Yasu da H, Gross SS, Levi R: $N^{G}$-methyl-L-arginine, an inhibitor of L-argininederived nitric oxide synthesis, stimulates renal sympathetic nerve activity in vivo: a role for nitric oxide in the central regulation of sympathetic tone? Circ Res 70:607-611, 1992

25. Zanzinger J , Czachurski J, Seller H: Inhibition of sympathetic vasoconstriction is a major principle of vasodilation by nitric oxide in vivo. Circ Res 75:1073-1077, 1994

26. Liu J L, Murakami H, Zucker IH: Angiotensin II-nitric oxide interaction on sympathetic outflow in conscious rabbits. Circ Res 82:496-502, 1998

27. Han S, Yang C-L, Chen X, Naes L, Cox BF, Westfall T: Direct evidence for the role of neuropeptide $Y$ in sympathetic nerve stimulation-induced vasoconstriction. AmJ Physi ol 274:H290-H294, 1998

28. Pedrazzini T, Seydoux J, Künstner P, Aubert J -F, Grouzmann E, Beermann F, Brunner H-R: Cardiovascular response, feeding behavior, and locomotor activity in mice lacking the NPY Y1 receptor. Nature Med 4:722-726, 1998

29. Stephens TW, Basinski M, Bristow PK, Bue-Valleskey J M, Burgett SG, Craft L, Hale J, Hoffmann J, Hsiung HM, Kriauciunas A, MacKellar W, Rosteck PR J r, Schoner B, Smith D, Tinsley FC, Zhang X-Y, Heiman M: The role of neuropeptide $Y$ in the antiobesity action of the obese gene product. Nature 377:530-532, 1995

30. Wu X, Makynen H, Kahonen M, Arvola P, Porsti I: Mesenteric arterial function 
in vitro in three models of experimental hypertension. I Hypertens 14:365-372, 1996

31. MorleyJ E, Mattammal MB: Nitric oxide synthase levels in obese Zucker rats. Neurosci Lett 209:137-139, 1996

32. Russell JC, Graham SE, Dolphin PJ, Amy RM, Wood GO, Brindley DN: Antiatherogenic effects of long-term benfluorex treatment in male insulin-resistant J CR:LA-cp rats. Atherosclerosis 132:187-197, 1997
33. Cardillo C, Kilcoyne CM, Quyyumi AA, Cannon III RO, Panza JA: Selective defect in nitric oxide synthesis may explain the impaired endothelium-dependent vasodilation in patients with essential hypertension. Circulation 97:851-856, 1998

34. Lyons D, Roy S, Patel M, Benjamin N, Swift CG: Impaired nitric oxide-mediated vasodilatation and total body nitric oxide production in healthy old age. Clin Sci 93:519-523, 1997 